\title{
O corpo a corpo com um sistema não se trata de abandoná-lo
}

\section{The confrontation against a system is not about abandoning it}

Dra. Ana Pato Curadora. Pesquisadora. Professora. Doutora em Arquitetura e Urbanismo pela Universidade de São Paulo E-mail: pato.ana@gmail.com ORCID: http://orcid.org/0000-0002-7733-7926

Dra. Joana Zatz Mussi
Artista. Pesquisadora. Educadora. Doutora em Arquitetura e Urba-
nismo
pela Universidade de São Paulo
E-mail: joanazatzmussi@gmail.com ORCID: https://orcid.org/0000-0003-2542-921X

\section{RESUMO:}

Este ensaio é um exercício de conversação e foi guiado por duas ideias: de um lado, a convicção de que estamos envolvidas por uma atmosfera marcada por diálogos impossíveis e que, diante da impossibilidade de falar sobre assuntos discordantes, de escutar os outros, de perceber para além de nós mesmas/os, estamos correndo em círculos, na tentativa de solucionar falsos problemas; de outro lado, o desejo de conversar mais sobre dúvidas que permeiam nossas pesquisas e práticas no campo da arte. Nesse diálogo, discutiremos as possíveis relações que podem ser estabelecidas entre a "arte engajada" e a "arte arquivista", acreditando que, assim, podemos formalizar publicamente um exercício de colaboração entre nós, que já existe há algum tempo e agora tem ganhado novos contornos.

Palavras-chave: Arte contemporânea. Crítica cultural. Arquivo. Engajamento.

PATO, Ana; MUSSI, Joana Zatz. o corpo a corpo com um sistema não se trata de abandoná-lo PóS:Revista do Programa de Pós-graduação em Artes da EBA/UFMG. v.9, n. 18: nov.2019

Disponível em < https://eba.ufmg.br/revistapos $>$ 


\section{ABSTRACT:}

This essay is an exercise in conversation and was guided by two ideas, on the one hand, the conviction that we are surrounded by an atmosphere marked by impossible dialogues, and that marked by the impossibility of talking about discordant issues, listening to others, perceiving others besides ourselves. Thus, we are running in circles, trying to solve false problems. On the other hand, the desire to talk more about doubts that permeate our research and practice in the field of art. In this dialogue, we discuss the possible relationships that can be established between "engaged art" and "archival art", believing that we can publicly formalize an exercise of collaboration between ourselves that has been around for some time and has now gained new contours.

Keywords: Contemporary art. Cultural Criticism. Archive. Activism.

Artigo recebido em: 31/05/2019 Artigo aceito em: 24/06/2019

PATO, Ana; MUSSI, Joana Zatz. o corpo a corpo com um sistema não se trata de abandoná-lo PóS:Revista do Programa de Pós-graduação em Artes da EBA/UFMG. v.9, n.18: nov.2019

Disponível em < https://eba.ufmg.br/revistapos $>$ 
Esse ensaio parte de uma colaboração que teve início quando as autoras faziam doutorado na FAU/USP. ${ }^{1}$ Durante o intenso processo de pesquisa que a elaboração e escrita de uma tese demandam, encontraram um tempo-espaço específico para o diálogo que travaram e, desde então, vêm travando de diferentes formas, a respeito da relação entre arquivo e engajamento na arte contemporânea.

Encontra-se aqui, portanto, mais uma aproximação possível entre os elementos que cada uma tem conseguido mobilizar desde o seu campo de estudo e de prática. Portanto, uma aproximação entre, por um lado: a mudança da função dos arquivos a partir do século 20 como modelo de institucionalização da memória no campo da arte; a prefiguração pela arte da violência contida nos arquivos, quando aquela desafia sua origem e, portanto, as formas por meio das quais os arquivos estruturam nossa realidade; a análise das diferentes formas de confrontação artística com essas questões e a operação na arte contemporânea de procedimentos historiográficos e não mais arquivísticos; e, por outro: a construção de um pensamento a respeito dos momentos em que a potência do encontro entre arte e política acaba por colocar em xeque modos de existência hegemônicos; a estética como estratégia de produção de inteligibilidade para situações liminares, ou o que o urbanista israelense Eyal Weizman conceitua como uma estética da evidência; o problema da materialidade das novas resistências como um fenômeno fundamental para a liberação de modos e formas que passem à margem das lógicas dominantes e neoliberais; o fato de que a potência política contemporânea precisa ser, para pôr novamente a nossa imaginação política para trabalhar, práxis criativa; e, finalmente, a necessária habilidade que um corpo precisa desenvolver para ocupar um certo ponto de vista, performatizar aquilo que está pensando, sentindo e interpretando dos fatos sociais e nos fazer ver coisas que, sem isso, não veríamos.

Interessante perceber o quanto os dois campos podem se relacionar e, ao mesmo tempo, quão distantes muitas vezes ficamos de discussões afins aos nossos problemas - seja por falta de acesso, de tempo, ou porque é mesmo impossível dar conta de tudo. No entanto, ao espelhar os problemas pensados por cada uma, estes se tornam até mais nítidos: a materialidade política ativada pelos

PATO, Ana; MUSSI, Joana Zatz. o corpo a corpo com um sistema não se trata de abandoná-lo PóS:Revista do Programa de Pós-graduação em Artes da EBA/UFMG. v.9, n. 18: nov.2019 Disponível em < https://eba.ufmg.br/revistapos $>$ 
movimentos contemporâneos, inclusive por meio da arte, tem uma exemplificação importante na retomada dos arquivos, que se tornam um mote central de todo um campo de problemas dos artistas e, com isso, forma de ativação da política pela arte. $O$ ato de prefiguração pela arte da violência contida nos arquivos, por sua vez, opera aqui como modo reverso de prefiguração, na medida em que a possibilidade de "imaginar algo fazendo este algo acontecer, e viceversa" ocorre por um ato não de di(solução) da violência, mas de sua liberação: confrontando os tabus daquilo que precisa ser visto, daquilo que precisa ser dito, é que algo de realmente novo pode surgir.

No fim, esse ato de colaboração é um exercício de aproximação que mais uma vez nos mostra o quão preciosa é a arte de construção de vizinhanças, não para arredondar problemas, ou mascará-los, ou mesmo adiá-los (afinal, cada vez mais sabemos que o apagamento do conflito só o faz retornar de modo cada vez mais violento). Mas pelo contrário, para que esse tipo de tensão produtiva desabroche questões mais profundas, nos faça rede, nos mostre campos de interdição fora, quiçá dentro da gente mesma.

\section{Arte e arquivo}

A proposta de repensar o conceito de arquivo a partir da arte contemporânea abre um campo vasto de análise, por isso, é necessário definir as bases desta pesquisa. Por que continuamos a falar de arquivo, hoje? De que tipo de arquivo estamos tratando? Por que o arquivo foi introduzido como modelo nas artes? Nesse contexto, mostraremos como uma arte arquivista se desdobra em uma arte historiográfica. E em que termos isso ocorre.

Ao propor tal introdução, é inexorável retomar a pergunta feita pelo filósofo Jacques Derrida (1930-2004): "Por que reelaborar, hoje, um conceito de arquivo?" (DERRIDA, 2001), proferida em 1994, na conferência intitulada: "O conceito de arquivo: Uma impressão freudiana", realizada na abertura do colóquio internaci-

PATO, Ana; MUSSI, Joana Zatz. o corpo a corpo com um sistema não se trata de abandoná-lo PóS:Revista do Programa de Pós-graduação em Artes da EBA/UFMG. v.9, n.18: nov.2019 Disponível em < https://eba.ufmg.br/revistapos $>$ 
onal Memória: a questão dos arquivos, em Londres, e organizado pela Sociedade Internacional de História da Psiquiatria e da Psicanálise, pelo Museu Freud e pelo Instituto de Arte Courtauld.

Sobre a pertinência da questão, hoje, ${ }^{2}$ destacamos o impacto causado pelos estudos políticos e culturais sobre a experiência da violência no século 20 e as práticas de memorialização criadas para lidar com o trauma, seja das ditaduras militares na América Latina, do apartheid na África do Sul ou dos campos de concentração na Segunda Guerra Mundial. Numerosos estudos sobre o tema resultaram na expansão do discurso sobre a memória ${ }^{3}$, em especial da memória traumática (AGAMBEN, 2008; ASSMANN, 2012; CARUTH, 1995; FELMAN, 2014; GANEBIN， 2006; HUYSSEN，2012; RICOUER， 2007; SELIGMANN-SILVA; NESTROVSKI, 2000).

O locus do arquivo como forma e conteúdo de experimentação artística a partir do início do século 20 e seus desdobramentos na arte moderna e contemporânea vêm sendo amplamente discutidos por autores como Alan Sekula, Hal Foster, Charles Merewether, Okwui Enwezor, Sven Spieker; no Brasil, Cristina Freire, Suely Rolnik, Márcio Seligmann-Silva, Priscila Arantes, Maria Angélica Melendi, entre outros.

A conceituação dos arquivos como modelos nas artes tem relação direta com as práticas artísticas que foram denominadas, pela história da arte ocidental, de Arte Conceitual ${ }^{4}$ (1960-1970). O foco desses artistas, na definição de seus trabaIhos, era expor e complexificar o poder do "sistema da arte": questões como os meios de produção e reprodução, os lugares de exibição da arte, as práticas utilizadas, as categorias definidas pela crítica de arte etc., enfim, um amplo leque de investigação que colocou em discussão os limites da criação inserida no sistema de arte e o esforço de romper essas fronteiras.

A tentativa de situar a lógica arquivista na produção contemporânea esbarra, necessariamente, no uso das categorias de apropriação ${ }^{5}$ e de citação. ${ }^{6}$ Para Benjamin Buchloh (2006) e Craig Owens (1980), a arte conceitual nos anos 1960

PATO, Ana; MUSSI, Joana Zatz. o corpo a corpo com um sistema não se trata de abandoná-lo PóS:Revista do Programa de Pós-graduação em Artes da EBA/UFMG. v.9, n.18: nov.2019 Disponível em < https://eba.ufmg.br/revistapos $>$ 
e início dos 70 representa o momento em que surgem as estratégias contemporâneas de apropriação e montagem, tributárias às características dos processos alegóricos e da leitura de Walter Benjamin (1892-1940). Sobre a experimentação com arquivos, não podemos nos esquecer do papel fundamental da literatura e as articulações do texto literário em reinvenções ficcionais ou documentais a partir de arquivos; refiro-me à produção de escritores como Jorge Luis Borges, Enrique Vila-Matas, W. G. Sebald, entre outros. ${ }^{7}$

Na opinião de Sven Spieker (2008), para compreendermos o “tipo de visualidade à qual o arquivamento é a chave", é preciso considerarmos os "arquivos burocráticos" ${ }^{8}$ como paradigma técnico-científico, por excelência, do projeto progressista de sociedade moderna. Da mesma forma como a crescente assimilação dos materiais - máquinas de escrever, fichários, fichas de inventário - pelos artistas é resultante do aumento massivo do volume de documentos administrativos produzidos entre 1870 e 1920, e a profusão desses acessórios para auxiliar o trabalho nos escritórios. Nesse aspecto, considera que os arquivos exercem a função de um laboratório experimental de investigação sobre o lado irracional da sociedade moderna, ${ }^{9}$ ao mesmo tempo em que fornecem "material" para a elaboração artística dessa premissa.

Para Achille Mbembe (2002), a definição de arquivo não pode ser suprimida de sua dimensão arquitetural; é nela que percebemos a construção da imaginação histórica, inscrita nas estantes geometricamente enfileiradas, na luz e umidade controladas, e nos procedimentos seguidos religiosamente. A questão da "materialidade dos arquivos" foi tratada com especial atenção pela historiadora Arlette Farge, em 0 sabor do arquivo (2009), ao descrever, minuciosamente, as sensações que observa e experimenta na práxis da pesquisa em arquivos e bibliotecas. Farge faz comparações entre a forma como o espaço é organizado e a tarefa do historiador.

Jean-Louis Déotte (1994), ao analisar o processo de criação das nações europeias, observa que compete ao Estado a implantação de uma "política de esquecimento", caso contrário, "corre o risco de se confrontar com um passado que

PATO, Ana; MUSSI, Joana Zatz. o corpo a corpo com um sistema não se trata de abandoná-lo PóS:Revista do Programa de Pós-graduação em Artes da EBA/UFMG. v.9, n.18: nov.2019 Disponível em < https://eba.ufmg.br/revistapos $>$ 
não quer passar". Para Achille Mbembe, a relação paradoxal que se estabelece entre preservar e abandonar os arquivos reside, justamente, na violência constitutiva do Estado, contida nos documentos armazenados nos depósitos legais. Se, por um lado, cabe à instituição preservar seus arquivos, por outro, o arquivo contém em si a própria ameaça a sua existência, pois garante a possibilidade de reconhecimento de uma dívida.

Para Seligmann-Silva (2014, p. 37), a desconfiança dos arquivos ao longo do século 20 é resultado do desmoronamento da razão ocidental e de sua capacidade de garantir uma vida civilizada; em vez do prometido triunfo, o processo civilizatório mostrou-se violento e genocida.

Em vez dos procedimentos de apropriação e manipulação das imagens para esvaziamento de seu significado anterior (a ideia do palimpsesto), dos riscos de perversão do conteúdo (o uso da citação corrompida) e das estratégias de acumulação compreendida como simples reunião de coisas aleatórias, percebemos que se trata de práticas de articulação e de reescrita. A hipótese de que estamos diante de um procedimento historiográfico e não arquivístico, teve como fundamento teórico a definição de Michel de Certeau (1925-1986), em A escrita da história. Segundo De Certeau (2013, p. 47), “a operação histórica se refere à combinação de um lugar social, de práticas 'científicas' e de uma escrita". O interesse particular em sua abordagem foi o entendimento de que "a escrita histórica permanece controlada pelas práticas das quais resulta", diz ele, "ela própria é uma prática social". É nesse sentido que considera ser impossível dissociar a constituição de um discurso histórico da instituição do saber a partir da qual ele se organiza.

Para De Certeau (2013, p. 64), a história seria "uma arte de discorrer que apagaria, pudicamente, vestígios de um trabalho". No conjunto dos procedimentos científicos que constituem a produção do texto histórico, o "trabalho" corresponderia à prática e à tecnicidade - considerados, no meio acadêmico, como "ciência auxiliar". Os arquivos modernos representariam, assim, o "complexo técnico", tendo como função ordenar, armazenar, preservar e dar

PATO, Ana; MUSSI, Joana Zatz. o corpo a corpo com um sistema não se trata de abandoná-lo PóS:Revista do Programa de Pós-graduação em Artes da EBA/UFMG. v.9, n.18: nov.2019 Disponível em < https://eba.ufmg.br/revistapos $>$ 
acesso aos dados da "coleção". Por sua vez, o "gesto do historiador" seria o de articular as técnicas (um modo de organização, os métodos de leitura e usos do documento) para, então, selecionar, recortar, copiar, transcrever e reunir os materiais a partir dos quais o texto histórico é criado. É nessa operação de deslocamento, diz ele, que o historiador transforma e desfigura os dados isolados por ele, com a finalidade de constituir documentos que possam completar as lacunas de um conjunto posto a priori.

Seguindo o caminho de suas ponderações, propomos a seguinte indagação: é um acaso que, no campo da arte, o procedimento arquivístico tenha se modificado em um procedimento historiográfico, no momento em que se impõe, por toda parte, uma desconfiança aos arquivos e ao modelo de racionalidade científica ${ }^{10}$ no início do século 21?

É na operação historiográfica que encontramos nosso desvio - a confrontação artística com o reconhecimento da violência contida nos arquivos e a realidade precária do estado de conservação de nosso patrimônio histórico resulta em práticas de reescrita que se produzem a partir do desejo de completar ausências, de criar novas interpretações, de deslocar e interromper a divisão entre um passado que não quer passar e um presente fraturado pela exclusão do outro. Presumimos, essa, uma arte historiográfica, por ter como determinação situar-se diante da "complexidade da fabricação histórica" para operar uma ação que não está fora de sua realidade, ela se assume como parte indissociável do "lugar" e do corpo social do qual faz parte.

Em tais operações, percebe-se que o artista que dedica sua prática aos arquivos não se posiciona contra "o sistema", ao contrário, deve observar e compreender seu funcionamento, suas limitações e urgências. Aliás, essas proposições têm seus efeitos ampliados ao embrenharem-se em negociações com as instituições para além do campo da arte. Afinal, para desatar a burocracia que os envolve, exige-se daquele que se aventura inculcar confiança à instituição e seus representantes. Essa relação é acentuada quando se trata de arquivos de violência.

PATO, Ana; MUSSI, Joana Zatz. o corpo a corpo com um sistema não se trata de abandoná-lo PóS:Revista do Programa de Pós-graduação em Artes da EBA/UFMG. v.9, n.18: nov.2019 Disponível em < https://eba.ufmg.br/revistapos $>$ 
No campo da arte brasileira, a potência dessas ações está em desbloquear regiões esquecidas para expor a incompreensão de um evento passado e criar memória a partir da experiência de integração de histórias obliteradas, no presente. Nesse aspecto, percebemos que a operação artística se desloca da "coleção" para a problematização trazida pelo próprio processo de confrontação com os "dados". O artista se movimenta entre a incompletude dos dados e o desejo de preencher as lacunas das narrativas históricas. Assim, ao lidar com a questão da representação e de suas formas de reinscrição, ele se utiliza de um conjunto de "estratégias pedagógicas" que tem como finalidade expor um ponto de vista e explicar os procedimentos de trabalho escolhidos na operação de (re)ligar "as ideias aos lugares".

Identificamos a vontade de compreender como se produz o conhecimento histórico e de assimilar as narrativas historiográficas como material de trabalho, o que acarreta extensos processos de pesquisa que transbordam para outras áreas de investigação. Por trás disso, manifesta-se a desconfiança nas narrativas produzidas pela história "oficial" e pelos meios de comunicação. Não à toa, essas práticas têm como propósito apresentar outras interpretações possíveis para os acontecimentos. É, nesse aspecto, que a prática historiográfica na arte brasileira atua na articulação e na redistribuição de informações, tendo como motivação fazer parte da realidade na qual está inserida.

Essas imagens nos foram gentilmente enviadas pela curadora israelense Galit Eilat, logo após o processo de realização do trabalho "Árvore-Escola"11 para a 31a Bienal de São Paulo, quando entabulamos uma série de conversas com ela a respeito da relação entre arte e política. A imagem oferece, assim, um exemplo que, para ela, manifesta uma zona indistinta, de trânsito, entre esses dois campos - da arte e da política. Segundo ela, às vezes, um trabalho está lidando com questões políticas, mas não é político porque não está de fato ativando o político. Portanto, um trabalho de "arte-política" é aquele que "Ativa o político e não o que fala sobre questões políticas. Aliás, em geral, eu prefiro não utilizar o termo 'arte-política', porque soa como um gênero da arte" (EILAT, 2015-2016).

PATO, Ana; MUSSI, Joana Zatz. o corpo a corpo com um sistema não se trata de abandoná-lo PóS:Revista do Programa de Pós-graduação em Artes da EBA/UFMG. v.9, n.18: nov.2019 Disponível em < https://eba.ufmg.br/revistapos $>$ 

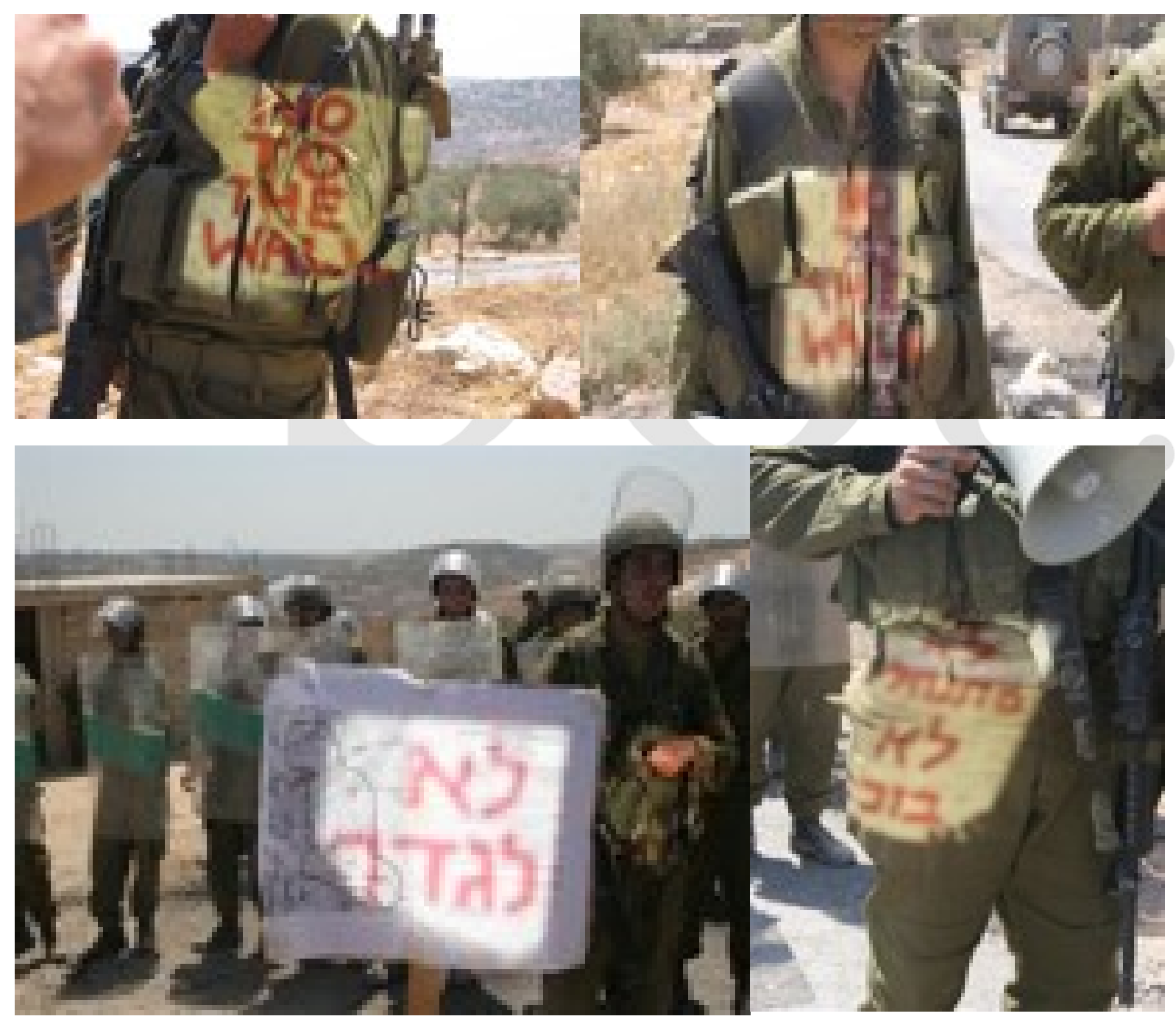

Fotografias 1, 2, 3, 4 - Palestinos projetaram imagens em soldados israelenses - [s.d.] Nota: palestinos projetaram com um espelho pintado a frase "soldados contra o muro" em soldados israelenses que controlavam os checkpoints (que são inúmeros e nos quais as populações palestinas são submetidas cotidianamente a situações de humilhação), transformando-os, por um instante, em uma espécie de "exército contra o muro". Sem data, autor anônimo.

Fonte: Arquivo Galit.

Escolhemos usá-la como um ponto de encontro improvável na construção de vizinhanças, que acontece quando desejos, saberes e fazeres se espelham, mesmo que esse espelhamento ocorra por meio de uma situação conflitiva. O espelho,

PATO, Ana; MUSSI, Joana Zatz. o corpo a corpo com um sistema não se trata de abandoná-lo PóS:Revista do Programa de Pós-graduação em Artes da EBA/UFMG. v.9, n.18: nov.2019 Disponível em < https://eba.ufmg.br/revistapos $>$ 
nesse caso, funciona como uma plataforma na qual é possível se movimentar, para expressar algo que não seria expresso a não ser pela lógica do espelhamento crítico.

O que no nosso texto se refere à inflexão de que todo conhecimento pressupõe um contexto. Qual a história do lugar? Qual a materialidade das relações sociais e políticas envolvidas? Como essas relações se reproduzem nas práticas e nos discursos? Chamamos atenção para o que Boaventura (2004, p. 25) alerta sobre o "risco de combinar denúncias radicais com a passividade de práticas ante as tarefas de resistência que se impõem".

\section{Arte e resistência}

Não é simples definir um campo de análise do qual partir quando falamos do encontro entre estética e política na atualidade, já que essa relação se dissemina de formas bastante diversas. A produção de espaços de convivência entre movimentos sociais e artistas, de ações interventivas, de imagens, são formas que se sobrepõem e aos poucos vão compondo todo um complexo campo de criação. Existem entradas (e saídas) diversas para esse mesmo problema e, por isso, é preciso sempre exercitar e pôr à prova uma multiplicidade de abordagens, a fim de construir um pensamento a respeito de quais práticas e processos emergem desse encontro.

Muitos pensadores que têm se debruçado sobre o problema das novas resistências admitem que a materialidade nelas presente é um fenômeno fundamental para a liberação de modos que escapam à lógica neoliberal. É da atividade coletiva concreta que deve sair a decisão coletiva, como dois elementos inseparáveis: não há, portanto, uma instância "abstrata" ou transcendente que supere ou seja mais importante do que a instância daquilo que está sendo realizado pratica mente. Assim, a potência política contemporânea se associa com uma práxis criativa que faz prevalecer a lógica experiencial. Se existe alguma possibilidade de potência política de resistência hoje, ela reside nesta dimensão livre, experi-

PATO, Ana; MUSSI, Joana Zatz. o corpo a corpo com um sistema não se trata de abandoná-lo PóS:Revista do Programa de Pós-graduação em Artes da EBA/UFMG. v. 9, n. 18: nov.2019 Disponível em < https://eba.ufmg.br/revistapos $>$ 
mental, que nasce da relação vital com o corpo e com o território; de uma efetiva ocupação de cada parte da vida social, de um habitar que liberta. Nesse sentido, é cada vez mais urgente pensar criticamente a relação entre as esferas micro e macropolítica para traçar e compreender possibilidades ou impossibilidades de rupturas na configuração política e econômica que se nos impõe. É constante o desafio em apreender a potência das revoltas, insurreições, rebeliões, ocupações, produções culturais e artísticas dissidentes ou contra-hegemônicas que temos visto nos últimos anos, no mundo todo, a fim de compreender onde reside sua força de escape ao sistema capitalista global.

É, nesse sentido, importante pensar em uma particular sensibilidade política que tem se desenvolvido nas últimas três décadas, difundida em diversos países por práticas críticas com forte caráter de intervenção no social e que não mais respondem ao sentido restrito de um "corpo coletivo organizado". São movimentos dissidentes que, em sua concretude e multiplicidade, passam a evidenciar urgências, especialmente da vida cotidiana, conectadas aos territórios. Por esse motivo, para traçar possíveis entendimentos desses movimentos, é preciso escutar, observar e conviver de perto com os atores políticos envolvidos nas lutas sociais contemporâneas; entender as ferramentas que constroem para agir, onde desenvolvem as suas ações, e como vão surgindo outros sentidos do que é revolução ou sua falência. É preciso olhar, conviver (e, por que não, ser) esse sujeito político múltiplo de hoje, para o qual a cidade é o grande campo de forças e de luta de classes, e não mais a fábrica.

Uma compreensão mais profunda sobre onde e como a política tem acontecido e também sobre onde e como a produção estética tem efetivamente ativado o político, tornando-se uma das peças-chave dos movimentos atuais de resistência, pode ser extraída da consolidação dessa imaginação política radical em situações de experimentação social que instalam um posicionamento em tempo real. Podemos também dizer que esse é um dos principais lugares de exercício da conexão entre arte e vida, hoje. Se pensarmos a indissociabilidade entre arte e política como uma das faces dessa relação, é fundamental olharmos diretamente para gestos, ações, discursos e concepções que surgem e circulam em torno

PATO, Ana; MUSSI, Joana Zatz. o corpo a corpo com um sistema não se trata de abandoná-lo PÓS:Revista do Programa de Pós-graduação em Artes da EBA/UFMG. v.9, n.18: nov.2019 Disponível em < https://eba.ufmg.br/revistapos $>$ 
desse tipo de situação. Desse modo, é possível perceber que, na aparente ausência de saída para a transformação social, o fazer pode dar acesso a uma dimensão que extrapola oposições ou clichês sobre o que é "política". Diversos movimentos estético-políticos tentam, assim, criar alternativas de rearticulação por meio de exercícios e experimentações que transformam os sujeitos em sujeitos políticos no próprio ato de constituição de modos de estar, de se relacionar, de fazer com os outros - o que, por sua vez, inaugura um domínio político no qual os possíveis se desdobram a partir do acontecimento.

A produção de processos de subjetivação que, de alguma maneira, fogem aos processos de subjetivação hegemônicos ocorreria, então, na elaboração de embates concretos, produzindo, com isso, um impasse no próprio ato de enunciar a possibilidade de um "espaço outro". Ao ocupar espaços em disputa, os "corpos" que a isso se dispõem incorporam o conflito. Nesse movimento, ao mesmo tempo em que há uma assunção do conflito e, portanto, uma tomada de posição que separa; há também, por aqueles que se dispuseram a publicizar uma determinada questão que poderia permanecer na invisibilidade, ou ter sido vivida como uma questão de ordem privada, uma liberação do corpo para o espaço social, pela qual diversas questões e experiências de ordem comum são devolvidas nesse âmbito.

Enunciar publicamente e tornar visível a constituição de uma verdade dissidente - ligada tanto a uma mutação subjetiva quanto a uma mutação coletiva - é uma forma de fazer a indeterminação circular. Portanto, a circulação não é apenas de resultados ou formas, mas da própria mutação de sensibilidade que resulta de um agenciamento coletivo.

Podemos criar um paralelo entre a visão foucaultiana e deleuze-guattariana de sujeito e subjetividade como processo de subjetivação - isto é, como dobra, o sujeito sendo objeto de si mesmo e não figura encerrada - e a face da imaginação coletiva que adentramos, entendida aqui como rompimento de formas fixas, expressão de agências que infletem o mundo quando nele intervém. É assim que o espaço se abre a partir de um corpo em transição: aquele que se

PATO, Ana; MUSSI, Joana Zatz. o corpo a corpo com um sistema não se trata de abandoná-lo PóS:Revista do Programa de Pós-graduação em Artes da EBA/UFMG. v.9, n.18: nov.2019 Disponível em < https://eba.ufmg.br/revistapos $>$ 
permite conhecer os espaços de conflito, ir até lá, instalar-se nesses lugares de uma forma ou de outra. Desse modo, uma posição política é produzida não como discurso vazio: uma posição muitas vezes inédita para o corpo e para o espaço, para o corpo no espaço, e a partir da qual são forjados outros usos que desafiam, na prática, os tempos e os espaços sociais. Permitir-se ser atravessado por essa indeterminação, inaugura, por sua vez, um tipo de contraconduta que responde aos modos como o poder opera atualmente que, em sua performatividade, quer encerrar toda a vida. Já dizia Foucault que as formas materiais de expressão do poder evidenciam mecanismos cada vez mais precisos de controle sobre a vida e a existência - algo que foi se acirrando ao longo dos últimos 50 anos. Daí a importância de produzir indícios dessa indeterminação: se a ação direta específica pode ser "vencida" - e, claro, em muitas dimensões o é, pelos poderes constituídos -, é possível acoplar aos contextos originais modos de estar que, desviantes, se inscrevem na memória social. O contexto se transforma, portanto, em sua materialidade-imaterialidade, passando a operar de outro modo na imaginação política coletiva: no mesmo movimento por meio do qual o contexto original adquire densidade - na medida em que experiências concretas inusitadas e dissidentes se somam a ele -, a sua atualidade material se virtualiza.

A resistência na atualidade ganha uma conotação muito forte de insistência em fazer existir e fazer continuar existindo modos de vida que são dissidentes em relação aos modos de vida hegemônicos, criando, apenas pelo fato de existirem, uma situação de conflito entre categorias e perspectivas de mundo. A instalação, nesse caso, entendida como categoria estético-política e existencial, pode ser considerada como um situar-se nos "entremundos", tornando evidente que existem mundos sendo disputados no interior do "nosso próprio mundo". É nas negociações entre esses mundos que batalham por se instalar com os mundos que não querem deixar se instalar mundos outros, ou que esses se façam evidentes, que se coloca a tentativa de tornar visível o próprio limiar que se produz nessa tensão. Existe, portanto, uma urgência efetiva em pensar na passagem entre as experiências da dissidência e a construção de evidências a partir delas, com o risco de que não se tornem inteligíveis e, assim, padeçam na

PATO, Ana; MUSSI, Joana Zatz. o corpo a corpo com um sistema não se trata de abandoná-lo PÓS:Revista do Programa de Pós-graduação em Artes da EBA/UFMG. v.9, n.18: nov.2019 Disponível em < https://eba.ufmg.br/revistapos $>$ 
condição de inexistentes. Para que esses “impossíveis" existam a partir de traduções à altura dos fenômenos que habitam o espaço do indeterminado, é necessário que haja a assunção da relação imanente entre ficção e realidade: captar algo que já é, mas ainda não é, mas já é, torna-se, assim, um desafio importante para a ativação do político pela arte.

\section{Representar o irrepresentável}

Como dizia Deleuze, "a arte é o que resiste ela resiste à morte, à servidão, à infâmia, à vergonha" (DELEUZE, 2010, p. 219). A arte é o que resiste também à representação. A arte resiste porque tem que deixar passar a força que tornou possível a sua própria existência. Para que isso aconteça, no entanto, precisam ser criados dispositivos de enunciação que permitam superar a fixação em formas que fazem sucumbir essa força vital. Dispositivos que deixem passar a espontaneidade rebelde e que consigam prolongar, em si, a força dos acontecimentos. Mas esse não é um trabalho qualquer. É um trabalho do desejo que orienta o escape da arte em si mesma, criando condições para a passagem das urgências sociais - as únicas capazes de quebrar o feitiço da cultura que nos anestesia (WRIGHT, 2015).

E os artistas que o produzem não são definitivamente especialistas, mas aqueles que conseguem esse efeito de sentido por meio de uma hibridação que acontece pela recusa de sua própria clausura como categoria. Para o Coletivo Situaciones, os especialistas são aqueles que dizem que se você faz política, faça política, e se você se dedica à arte, não faça política, porque na arte estão os que manejam a linguagem visual e a estética e podem dizer o que é arte e o que não é. O especialista funciona, portanto, por categorizações que separam e descontextualizam o que se produz subsumindo-o na linguagem fechada de um "campo" que se pretende autônomo e específico (SITUACIONES, 2016).

PATO, Ana; MUSSI, Joana Zatz. o corpo a corpo com um sistema não se trata de abandoná-lo PóS:Revista do Programa de Pós-graduação em Artes da EBA/UFMG. v.9, n.18: nov.2019 Disponível em < https://eba.ufmg.br/revistapos $>$ 
Acreditamos que muito pode ser pensado a respeito da relação entre arte e política hoje - mais precisamente, sobre o sentido dessa conexão -, a partir de situações disparadoras que nos permitem enxergar questões latentes quando se trata de classificar aquilo que pretensamente deve estar "dentro" das instituições da arte (ou da arte como instituição) e o que deve manter-se "fora" delas. Além do mais, se a arte nos faz enfrentar permanentemente a tensão entre a representação e o irrepresentável - sendo, por isso, campo fértil para compreender o fazer político de outros modos e ampliar a percepção dos espaços nos quais a política tem sido ativada como potência -, as falas, dúvidas, reflexões, embates e ações produzidos nesse âmbito podem ser úteis para pensarmos essa relação sempre difícil entre o instituinte e o instituído em qualquer espaço formal de representação.

É nesse sentido que entendemos haver uma responsabilidade também daqueles que estão nas instituições, no sentido de abri-las, de transformá-las em instituições capazes de lidar com a força daquilo que está se constituindo, com as fugas da representação. As instituições não são, definitivamente, "entes abstratos", mas efeitos do trabalho de pessoas e coletivos de pessoas que preferem identificar-se ou que se propõem de muitas formas a desidentificar-se em relação a elas - e a pagar um preço por isso.

\section{O papel do corpo}

Uma provocação feita pelo artista Amilcar Packer (2015) ajuda a pensar, nesses termos, o que pode ser considerado o papel do artista-ativista (e, inversamente, ou igualmente, do ativista-artista), hoje. Para ele, o artista-ativista deve estar à margem e não ser herói (fazendo referência a Hélio Oiticica em seu trabalho Seja Marginal Seja Herói), firmando-se em seu papel e em sua função que seria a de colaborar na radicalização da imaginação política - meio de exigência e invenção do impossível. Em termos de produção enunciativa, Amilcar aposta na potência do caráter não representativo que pode ser acionado em enunciados performa-

PATO, Ana; MUSSI, Joana Zatz. o corpo a corpo com um sistema não se trata de abandoná-lo PóS:Revista do Programa de Pós-graduação em Artes da EBA/UFMG. v.9, n.18: nov.2019 Disponível em < https://eba.ufmg.br/revistapos $>$ 
tivos. Seu questionamento é, no fundo, sobre a capacidade e a coragem que têm tido os artistas, mesmo aqueles considerados engajados, de inscrever a imaginação política radical a partir de seus enunciados, pois isso significa a construção de posições efetivas no mundo, não meramente representacionais ou predicativas.

Daí o motivo da disputa entre esse tipo de ação enunciativa e enunciações que podemos considerar hegemônicas se dar em torno do lugar do corpo: porque enquanto as enunciações hegemônicas, para garantir que nada mude, procuram se apoiar em abstrações previamente construídas e, portanto, desincorporadas, as insurgentes tentam garantir que nós, como corpos que somos, possamos produzir anúncios incorporados que se iniciam na escala da intimidade, em que ainda encontramos e nos conectamos com uma força imprevisível que configura o espaço de gestação e a fonte do gesto (HOLMES, 2009). É nesse sentido que um processo de politização se dá somente na medida em que nos reapropriamos da potência do gesto em sua não binariedade: um modo de exercício da política que tem como principal função lembrar-nos incansavelmente que existem corpos por trás dos monumentos, dos parlamentos, das leis, das bibliotecas, das escolas, dos arquivos, das universidades e das instituições de arte... E que, afinal, se são corpos, em sua (in)significância, que inventam o que é patrimonializável ou não, representável ou não, quais as formas e conteúdos legítimos da aprendizagem ou não, que decidem quem merece viver e quem deve morrer, são também corpos que podem questionar e/ou abdicar dessas invenções e decisões.

A respeito disso, Butler e Athanasiou, em Dispossession: The Performative in The Political (2013), apontam para o performativo no político como aquilo que resiste à assimilação e para a importância de gestos que tornem essa resistência inteligível. Nesse sentido, é a própria vida que se torna terreno de produção estéticopolítica, o que exige fazer o que se diz no próprio espaço sobre o qual se diz, já que o imaginado está colado à necessidade de fazer nascer novas linguagens, resultado de conexões efetivamente estabelecidas no mundo. O teórico e curador Stephen Wright diz que há um "trabalho" envolvido nesse tipo de ação, uma precisão necessária ao gesto, a partir da qual circula-se e socializa-se uma

PATO, Ana; MUSSI, Joana Zatz. o corpo a corpo com um sistema não se trata de abandoná-lo PÓS:Revista do Programa de Pós-graduação em Artes da EBA/UFMG. v.9, n.18: nov.2019 Disponível em < https://eba.ufmg.br/revistapos $>$ 
competência artística que põe em xeque e subverte a lógica própria da arte ao torná-la "uma caixa de ferramentas que pode ser refeita a cada momento e desafia o propósito das coisas" (WRIGHT, 2014). A arte pode tornar-se ferramenta ao ser manipulada das mais diversas formas, por exemplo, quando “imagens são levadas para as manifestações dentro dos corpos. [Porque] não são apenas representações de uma realidade pré-existente, mas coisas que permitem às pessoas interpretar e agir no mundo" (FAULKNER, 2013, p. 2). Por isso, vemos, hoje, que, em certos momentos, uma instalação, uma performance, uma ocupação, um conceito, uma situação de aprendizagem, uma residência artística, um livro, um arquivo, ou uma imagem mediada etc., ao constituir a arte de operar territórios afetivos e torná-los visíveis, podem vir a balizar mudanças reais ou possíveis em relação às leis, costumes, comportamentos, medidas, dispositivos organizacionais ou técnicos que definem como devemos nos comportar e relacionar uns com os outros (HOLMES, 2009).

De acordo com Agamben (2016), assistimos à nossa própria ruína, à nossa dessubjetivação, em zonas cotidianas muito banais, nas práticas de cada um, em diversos aspectos de nossas vidas corporais. É justamente nessas zonas que podemos produzir uma densidade de pensamento, de afeto, de delicadeza, de organização, capazes de trazer uma atenção aos fenômenos que suscitem qualidades completamente diversas da impaciência e da negligência, vistas e sentidas nas forças da ordem: "habitar plenamente é tudo o que podemos opor ao paradigma do governo" (COMITÊ INVISÍVEL, 2016, 197). Essas zonas cotidianas são compostas de agenciamentos entre corpos, entre corpos e superfícies urbanas, corpos e elementos do espaço, porque é na subversão do uso e nos "usos sem direito" que se produzem contracondutas - "tu permaneces escravo mas, uma vez que faz uso dessa condição, no modo do como não, tu não és mais escravo" (AGAMBEN, 2016, p. 12).

Em tempos de estrangulamento do estado de delicadeza, levado a cabo pela agenda radicalmente neoliberal e cada vez mais autoritária, que dissemina um léxico de gestos e discursos ao mesmo tempo brutos e vazios, é urgente cartografar e refletir a partir da produção de línguas e linguagens com espessura, com

PATO, Ana; MUSSI, Joana Zatz. o corpo a corpo com um sistema não se trata de abandoná-lo PóS:Revista do Programa de Pós-graduação em Artes da EBA/UFMG. v.9, n.18: nov.2019 Disponível em < https://eba.ufmg.br/revistapos $>$ 
densidade, que carreguem agências, potências e também as radicalidades presentes nos estados liminares, nas encruzilhadas, portanto, naquilo que representa alternativas, e não a falta delas.

Se, por um lado, temos nos parlamentos, nas assembleias, nos espaços formais do poder, um esvaziamento da palavra e das linguagens, em última instância, da imaginação política coletiva, causado pela associação total entre Estado, Capital e ideologias as mais reacionárias, que investem em matar a possibilidade de uma enunciação singular e carregada de corpo; por outro, temos muitas e diversas experiências, mesmo no interior dos parlamentos, de abertura de tempos e espaços nos quais a enunciação não está deslocada da experiência material do corpo, dos laços e vínculos afetivos, da criação de um mundo outro.

Se estamos falando da produção de corpos que se politizam no corpo a corpo com aquilo que parece encerrado (dispositivos de poder: formas, leis, gestos), criando a partir disso desvios imprevisíveis (BUTLER, 2018), entendemos por que a forma do protesto nesse âmbito, ou aquilo que pode ser compreendido enquanto tal, não corresponde a um corpo coletivo organizado como corpo hegemônico, mas passa a ser reflexo dessa busca por menos palavras de ordem e mais modos de estar e enunciações que, em sua organicidade, captam uma sensibilidade coletiva, digam dela. Mais importante do que o grito, se torna a produção de evidências para uma perspectiva do mundo que traz à tona a prova da multiplicidade em gestos, em sentidos até banais, cotidianos, e que partem de dimensões materiais para, então, explodi-las com a força destes corpos.

A perspectiva que produz estas existências não corresponde, portanto, a pontos de vista abstratos, mas corporais. Para explicar isso, a antropóloga dinamarquesa Stine Krøijer (2013) cria uma relação entre esse tipo de ativismo presente de modo mais disseminado a partir dos anos 2000 e, ainda mais profundamente a partir dos ciclos de protestos iniciados em 2011, com o perspectivismo ameríndio descrito pelo antropólogo brasileiro Eduardo Viveiros de Castro (2013). De acordo com Krøijer, se é óbvio que as cosmologias de um ativista europeu, que é o caso estudado por ela, e dos indígenas amazonenses, são muito diferentes, a sua

PATO, Ana; MUSSI, Joana Zatz. o corpo a corpo com um sistema não se trata de abandoná-lo PóS:Revista do Programa de Pós-graduação em Artes da EBA/UFMG. v.9, n.18: nov.2019 Disponível em < https://eba.ufmg.br/revistapos $>$ 
capacidade corporal de ocupar um ponto de vista é análoga. Isso, por sua vez, não significa que um mesmo mundo está sendo visto por diferentes ângulos, mas que o mundo varia a partir desta instalação corporal num determinado lugar, que condiz com a produção de todo um modo existencial. Podemos estender essa percepção para compreender uma sensibilidade de engajamento mais ampla nos dias atuais, que têm como fundamento a percepção da importância de ocupar uma perspectiva corporalmente para poder transformá-la na evidência de uma existência.

Acionar uma inteligibilidade é, aqui, forma de tornar pública uma experiência, processos de "fazer-se" e fazer mundos e de "fazer este fazer-se aparecer". É assim que nos deparamos com a invenção de formas que nascem necessariamente de usos singulares do espaço e das coisas do mundo, usos que somente um corpo pode experimentar, desafiando, ao fazê-lo, a imaginação coletiva, ou seja, a nossa própria ideia do que é ou não é possível. Um corpo cria, ao ocupar, uma situação única, capaz de desfigurar tudo, produzir texturas, intensidades, cortar, colar, romper. Porque é um corpo que pode ver, ouvir, dizer, pensar, anarquivar o passado e devir o futuro. E, nesse sentido, é esse corpo ativo que tenta a todo custo nos mostrar o mundo que está vendo.

\section{Estética da evidência}

Este termo foi cunhado pelo arquiteto, acadêmico e escritor israelense Eyal Weizman em conexão com a sua pesquisa a respeito do papel central da arquitetura na ocupação israelense da Palestina, usando também os danos causados às edificações como evidências de crimes de guerra.

Em junho de 2010, foi organizado por esse pensador e realizado pelo Centre for Research Architecture Goldsmith University and the Centre Europe-Tiers Monde no Conselho de Direitos Humanos da ONU, em Genebra, o seminário The Aesthetic of Evidence, ${ }^{12}$ no qual diversos pensadores abordam a passagem, nos últimos anos, da lógica do testemunho para a lógica da evidência, possibilidade aberta pelas

PATO, Ana; MUSSI, Joana Zatz. o corpo a corpo com um sistema não se trata de abandoná-lo PóS:Revista do Programa de Pós-graduação em Artes da EBA/UFMG. v.9, n.18: nov.2019 Disponível em < https://eba.ufmg.br/revistapos $>$ 
formas atuais de produção de conhecimento, dentre elas as tecnologias de visualização (GPS, ciber-vídeo, bio-evidências etc.). Weizman se pergunta, durante o seminário, como fica a questão ética nessa passagem, chamando a atenção para um primeiro problema a ser levado em conta: os usos dessas novas tecnologias não podem, apesar de complementares ao testemunho, simplesmente substituírem-no, com o risco de que a "estética" se transforme em "estetização" e sejam anuladas as diferenças entre uma e outra. A estética, segundo ele, tem a ver com uma intervenção no campo geral do sensível, naquilo que pode ou não ser visto, ser ou não ouvido e em seus efeitos na vida social. Tem a ver, portanto, com como algo passa a ser visto ou ouvido, se tornando legível, em um movimento de "legibilização" que cria um tipo de atenção à forma como as evidências são mobilizadas e apresentadas.

A construção da evidência é o que deixa claro que as evidências são sempre "dispositivos" e não peças ou molduras de uma narrativa "autoevidente". Há um trabalho social que se constrói para que os mecanismos de uma estrutura muito mais ampla que sustenta a ideia das "verdades autoevidentes", assim como, analogicamente, o que a jornalista Eliane Brum vem nomeando de "auto verdades" (BRUM, 2019), possam ser desconstruídos, ou, ao menos, desafiados.

A respeito disso, Frederik Tygstrup, professor do Departamento de Artes e Estudos Culturais da Universidade de Copenhagen, tematiza o termo "estética da evidência" naquilo que este remete para um certo embaçamento de fronteiras entre fato e ficção, já que por "fatos" não mais entendemos apenas algo que tenha o real como referencial; assim como na ficção se vê a necessidade que se coloca, hoje, de assunção de que os discursos, no fim, são todos fabricados. Indexal e ficcional, segundo ele, hoje, se fundem, se confundem, podendo um ser tomado pelo outro. Uma ficção intervém na realidade, assim como um fato pode produzir ficções, e assim por diante. Nesse sentido, a constituição de uma estética da evidência teria a ver com criar ferramentas de visibilização em um momento no qual está muito difícil estabelecer fatos e é preciso confrontar as manipulações derivadas de todo o aparato constitutivo do mundo das fake news. $\mathrm{O}$ ato de verificação dos fatos se torna fundamental. Todavia, esse processo de veri-

PATO, Ana; MUSSI, Joana Zatz. o corpo a corpo com um sistema não se trata de abandoná-lo PÓS:Revista do Programa de Pós-graduação em Artes da EBA/UFMG. v.9, n.18: nov.2019 Disponível em < https://eba.ufmg.br/revistapos $>$ 
ficação não significa simplesmente estabelecer objetividade em meio a um mundo de incertezas. Significa, sim, a possibilidade de construir uma concepção da verdade que desafia a ideia de que certas instituições seriam mais aptas a produzir "a verdade", ou seja, a ideia de que a verdade é efeito de uma perspectiva única.

No trabalho do Forensic Architecture, portanto, dá-se a ver políticas de produção da verdade para dar a ver a dimensão política daquilo que consensuamos coletivamente como verdade. Esta política de produção da verdade vira, em si, linguagem, a linguagem que compõe o trabalho do grupo e uma expertise que estabelece modos de verificação do real ao colocar em xeque pela arte, por um lado, verdades absolutas e, por outro, a pós-verdade que temos assistido hoje.

Por último, mas não menos importante, Weizman explica que, etimologicamente, o termo forense vem de "fórum". Ou seja, essa terminologia carrega, em sua origem, o entendimento de que tanto a "produção da prova" ou "da evidência" devem ser atos políticos, como o seu cotejamento deve ser feito politicamente, em domínio público, provocando situações de debate e reflexão social frente a uma determinada situação. O deslocamento do forense para o fórum nos permite compreender que a produção e a análise de evidências devem ser motores de debate social, abrir espaços de fala e escuta, e não fechá-los; promover a formação de inteligências mobilizadoras da sociedade e não desmobilizadoras, que é o que acabam sendo quando expropriadas como um fazer que, especializado, se dá em zonas obscuras e a portas fechadas.

\section{Conclusão}

Nossa colaboração se reverte, hoje, numa ação curatorial e artística para a realização da exposição Meta-arquivo: 1964-1985. Espaço de escuta e leitura de histórias da ditadura, ${ }^{13}$ da qual Ana Pato é curadora e Joana Zatz Mussi é artista convidada com o Grupo Contrafilé. A exposição é sobre imaginar coletivamente os processos de construção da história brasileira. É disso que trata o programa

PATO, Ana; MUSSI, Joana Zatz. o corpo a corpo com um sistema não se trata de abandoná-lo PóS:Revista do Programa de Pós-graduação em Artes da EBA/UFMG. v.9, n. 18: nov.2019 Disponível em < https://eba.ufmg.br/revistapos $>$ 
de ação curatorial que Ana desenvolve desde 2014, com a articulação de pesquisas artísticas e a formação de grupos de trabalho em torno de arquivos e acervos. No Brasil, nos deparamos com a invisibilidade, o abandono e o risco de apagamento dos acervos documentais e artísticos - não podemos esquecer das imagens recentes do Museu Nacional em chamas. Meta-Arquivo se articula no desejo de repensar as instituições de memória e suas práticas e mobilizar processos de pesquisa em arte, para a criação de espaços de escuta e reflexão sobre a experiência histórica traumática brasileira. Tendo isso em vista, propomos um gesto coletivo de engajamento nessas instituições. Suas questões norteadoras são: Como construir um arquivo? Como torná-lo público? Como falar do trauma? Como o imaginário da ditadura civil militar brasileira poderia ser integrado ao que sentimos e pensamos ser, hoje, o nosso presente?

O recorte temporal foi escolhido para delimitar o nosso processo de escavação e aproximar os artistas do trabalho lento e gradual de abertura dos arquivos da última ditadura. Mover-se na linha do tempo é sempre uma tarefa difícil, pois que a linha do tempo se torna traiçoeira quando lutamos para lembrar das histórias dos traumas, que envolvem genocídios, apagamentos e, portanto, negação e desconfiança.

Porque quando se mergulha em arquivos históricos, o que se vê é uma continuidade reveladora de processos de exclusão social e política, porém, percebe-se também a complexidade das questões. Na tessitura dessa trama, os dualismos se mostram cada vez mais insuficientes. Não por acaso, durante as atividades do grupo de trabalho Meta-arquivo, o que era uma imersão em arquivos da ditadura passou a ser atravessada diariamente por narrativas que surgem de todos os lados, ocupam os noticiários, as conversas de bar, os almoços em família e as conversas entre nós. Pelo que lembramos, nunca se falou tanto sobre a ditadura no Brasil. A psicanálise e os estudos da memória nos mostraram que, se não reconhecemos as injustiças nas sociedades, se não nomeamos os genocídios cometidos pelo Estado, se não sepultamos nossos mortos, não há reconciliação possível com o nosso passado, estamos destinados ao medo e a repetição das nossas histórias de horror. "Mas, na época em que a verdade se tornou uma

PATO, Ana; MUSSI, Joana Zatz. o corpo a corpo com um sistema não se trata de abandoná-lo PÓS:Revista do Programa de Pós-graduação em Artes da EBA/UFMG. v.9, n.18: nov.2019 Disponível em < https://eba.ufmg.br/revistapos $>$ 
escolha pessoal, como respeitar os fatos?", pergunta Eliane Brum. O que buscamos são momentos de clareza! É o que nos lembra Susan Buck-Morss ao pensar as ausências em torno da Revolução Haitiana: "E, se, a cada vez que a consciência dos indivíduos ultrapassasse os limites das constelações atuais de poder e percebesse o significado concreto da liberdade, este fosse avaliado como um momento, ainda que transitório, da realização do espírito absoluto?" (BUCKMORSS, 2017)

Neste contexto, o Grupo Contrafilé foi interpelado pelos relatos do Programa Regular da Coleta de Testemunhos, do Memorial da Resistência. Escolheu, com isso, se dedicar à escuta desses testemunhos, problematizando a partir disso o estatuto do corpo e de suas experiências como documentos históricos, assim como o estatuto daquele corpo que encontra com esses corpos-documentos: o que encontramos quando nos encontramos com os arquivos? O que aprendemos com eles? E como? Afinal, nesse processo acontece uma espécie de confronto entre corpos, mas de uma forma diferente de quando os dois corpos entram em um embate mais ou menos físico, porém estando os dois presentes materialmente.

De qualquer forma, talvez seja possível arriscar dizer tanto que esse tipo de estética pode ser denominada como uma "estética da evidência", nos termos de Weizman - no momento em que aquele corpo deste tempo vê, ouve, acessa determinadas perspectivas do corpo outro, que também fez um esforço enorme para falar a partir de uma perspectiva nascida do trauma para evidenciá-la; quanto que esta não visa a produção "da" verdade, mas de um substrato de operações a partir das quais seja possível instalar dúvidas nas verdades instituídas, dúvidas que permitam pensar o mundo das zonas de guerra e dos conflitos, ou seja, em sua radicalidade, rompendo com os mecanismos que naturalizam concepções "do que pode ter realmente acontecido" - o que transmuta, consequentemente, a capacidade de imaginar coletivamente o futuro, ou seja, o que poderá, ou não, acontecer. Há, portanto, um investimento no papel da arte para a ampliação das possibilidades de compreensão dos "fatos sociais" e, assim, para que o debate que politiza e poetiza a produção da evidência possa ir para o

PATO, Ana; MUSSI, Joana Zatz. o corpo a corpo com um sistema não se trata de abandoná-lo PóS:Revista do Programa de Pós-graduação em Artes da EBA/UFMG. v.9, n.18: nov.2019 Disponível em < https://eba.ufmg.br/revistapos $>$ 
centro da aprendizagem social, mostrando que os "fatos" devem ser construídos pelo embate entre diferentes perspectivas corporais diante do mundo, em arranjo com as possibilidades técnicas e tecnológicas, com os dispositivos do direito, da arte e da pedagogia, pois tudo isso modifica a interpretação das evidências, mas antes, sua produção e, depois, seus efeitos no imaginário. Estamos aqui, entre o tribunal e o parlamento: abrimos fatos e produzimos evidências para poder conversar sobre eles. Aqui, trabalhos artísticos produzem linguagem ao escavar fatos, trazendo à tona, nesse movimento, a questão do direito à representação como lugar por excelência onde as esferas da arte e da política se encontram hoje.

Enfim, talvez seja buscando clareza que possamos encontrar a possibilidade de contaminação uns dos outros pelas formas (de ser, de fazer, de pensar, etc.). Uma contaminação que força, mesmo que por momentos breves, uma ruptura com o que Brian Holmes chama de "caráter zumbi" da sociedade neoliberal. Essas formas são, portanto, formas de impossibilitar a cegueira, de "ativar as forças humanas e exumar as forças humanas abafadas" (WRIGHT, 2014).

PATO, Ana; MUSSI, Joana Zatz. o corpo a corpo com um sistema não se trata de abandoná-lo PóS:Revista do Programa de Pós-graduação em Artes da EBA/UFMG. v.9, n. 18: nov.2019 Disponível em < https://eba.ufmg.br/revistapos $>$ 


\section{REFERÊNCIAS}

AGAMBEN, Giorgio. Uma Biopolítica Menor. São Paulo: n-1 2016.

ARGAN, Giulio. Arte Moderna. Tradução: Denise Bottmann; Federico Carotti. São Paulo: Companhia das Letras, 1992.

BUCK-MORSS, Susan. Hegel e o Haiti. Tradução: Sebastião Nascimento. São Paulo: N-1 edições, 2017. [Publicado originalmente em 2000].

BUTLER, Judith. Corpos em aliança e a política das ruas - Notas para uma teoria performativa de assembleia. Rio de Janeiro: Civilização Brasileira, 2018.

BUTLER, Judith; ATHANASIOU, Athena. Dispossession: The Performative in the Political. Cambridge/Malden: Polity Press, 2013. p. 13.

DE CERTEAU, Michel. A escrita da história. Tradução: Maria de Lourdes Menezes. Rio de Janeiro: Editora Forense Universitária, 2013. [1ª ed. 1975.]

DERRIDA, Jacques. Mal de arquivo: uma impressão freudiana. Tradução: Cláudia de Moraes Rego. Rio de Janeiro: Relume Dumará, 2001. [Publicado originalmente em 1995].

DÉOTTE, Jean-Louis. Oubliez! Les Ruines, L'Europe, Le Musée. Paris: Éditions L'Harmattan, 1994.

COMITÊ INVISÍVEL. Aos nossos Amigos - Crise e Insurreição. São Paulo: N-1, 2016.

COLECTIVO SITUACIONES. Politizar a tristeza. Global, Rio de Janeiro, n. 8, p. 22-23, mar./ abr./maio, 2007. Disponível em: <http://www.sindominio.net/eldinerogratis/TEXTOS/Politizar \%20la\%20tristeza.htm>. Acesso em: 15 maio 2016.

DELEUZE, Gilles. Controle e Devir. Conversações. São Paulo, Ed. 34, 2010.

FAULKNER, Simon. Images and Demonstrations in the Occupied West Bank. JOMEC Journal: Journalism, Media, and Cultural Studies, n. 4, nov. 2013.

FORENSIC ARCHITECTURE. Forensis - The Architecture of Public True. Berlim: Sternberg Press and Forensic Architecture, 2014.

HOLMES, Brian. Escape the Overcode - Activist art in the control society. Eindhoven, Zagreb, Istanbul: Van Abbemuseum/WHW, 2009.

KRØIJER, Stine. Figurações do Futuro. Da forma e temporalidade dos protestos entre ativistas da Esquerda Radical na Europa. Alegrar, Dossiê Na rua | Em movimento, Curitiba, n. 12, dez. 2013.

MBEMBE, Achille. Necropolítica. São Paulo: n-1, 2018.

MBEMBE, Achille. Crítica da Razão Negra. São Paulo: n-1, 2018.

PATO, Ana; MUSSI, Joana Zatz. o corpo a corpo com um sistema não se trata de abandoná-lo PóS:Revista do Programa de Pós-graduação em Artes da EBA/UFMG. v.9, n. 18: nov.2019

Disponível em < https://eba.ufmg.br/revistapos $>$ 
MBEMBE, Achille. The Power of the Archive and its Limits. In: HAMILTON, Carolyn; HARRIS, Verne; TAYLOR, Jane; PICKOVER, Michele; SALEH, Razia; REID, Graeme. (ed.) Refiguring the Archive. Cape Town, South Africa: David Philip Publishers, 2002.

Mussi, Joana Zatz. Arte em Fuga. 2017. Tese (Doutorado em Projeto, Espaço e Cultura) Faculdade de Arquitetura e Urbanismo, Universidade de São Paulo, São Paulo, 2017. doi:10.11606/T.16.2018.tde-11012018-122950.

PATO, Ana Mattos Porto. Arte contemporânea e arquivo: como tornar público o arquivo público?. 2017. Tese (Doutorado em História e Fundamentos da Arquitetura e do Urbanismo) - Faculdade de Arquitetura e Urbanismo, Universidade de São Paulo, São Paulo, 2017. doi:10.11606/T.16.2018.tde-13062017-115843.

PETTI, Alessandro; HILAL, Sandi; WEIZMAN, Eyal. Architecture After Revolution. Berlim: Sternberg Press, 2013.

SANTOS, Boaventura Sousa. Um discurso sobre as ciências. Porto: Edições Afrontamento, 1988.

SANTOS, Boaventura Sousa. Do pós-moderno ao pós-colonial. E para além de um e outro. CONGRESSO LUSO-AFRO-BRASILEIRO DE CIENCIAS SOCIAIS, 7., realizado em Coimbra, de 16 a 18 de setembro de 2004. Conferência de Abertura. Disponível em: http://www.ces.uc.pt/misc/Do_pos-moderno_ao_pos-colonial.pdf. Acesso em: 2 jan. 2017.

SELIGMANN-SILVA, Márcio. Sobre o anarquivamento - um encadeamento a partir de Walter Benjamin. Revista Poiésis, n. 24, p. 35-58, dez. 2014.

SPIEKER, Sven. The Big Archive: art from bureaucracy. Cambridge, Massachusetts: The MIT Press, 2008.

WEIZMAN, Eyal. Aesthetic of Evidence. Genebra, 2010. Seminário disponível no site Forensic Architecture, Disponível em:

http://www.forensic-architecture.org/seminar/aesthetics-of-evidence/.

WRIGHT, Stephen. Toward a Lexicon of Usership. Texto presente no site do Van Abbemuseum, de Eindhoven, Holanda. Disponível em: http://museumarteutil.net/tools/. Acesso em: 20 jan. 2015. [Tradução nossa].

PATO, Ana; MUSSI, Joana Zatz. o corpo a corpo com um sistema não se trata de abandoná-lo PóS:Revista do Programa de Pós-graduação em Artes da EBA/UFMG. v.9, n.18: nov.2019 Disponível em < https://eba.ufmg.br/revistapos $>$ 


\section{NOTAS}

1 Ambas defendidas em 2017, com os títulos: PATO, A. M. P. Arte contemporânea e arquivo: como tornar público o arquivo público? e Mussi, J. Z. Arte em Fuga.

2 Cabe considerar que, no campo da arquivística, o paradigma do acesso aliado à questão da tecnologia trouxe novas exigências tanto à prática dos arquivistas como à cadeia de transmissão de conhecimentos (MENNE-HARITZ, 2001; LEMAY, 2009; KLEIN; LEMAY, 2012). É sob esse aspecto que Wolfgang Ernst (2015) problematiza a vocação dos estudos da arquivologia (germânica) contemporânea, ao enfatizar o armazenamento de documentos, no sentido de atender a administração governamental, em vez de ter um propósito historiográfico. Para tanto, propõe aproximar o pensamento filosófico francês, em Michel Foucault, Michel de Certeau, Gilles Deleuze, Jacques Derrida, François Furet e Arlette Farge, sobre o conceito de arquivo das pesquisas ligadas à arqueologia da mídia (escola que enfoca os estudos cibernéticos da memória). Enquanto, no campo da arte, a necessidade de revisão metodológica dos procedimentos de conservação de arte contemporânea levou museus e instituições culturais a dar destaque à questão da deterioração e efemeridade de suas coleções (STRINGARI, 2003; LAURENSON, 2006; JONES, 2010; DEKKER, 2010; SEHN, 2010).

3 Para uma compreensão da abrangência dos estudos de "memória cultural", ver Aleida Assmann. Cabe lembrar que a relação entre cultura e os usos da memória é antiga e remonta à arte da memória e ao estudo da mnemotécnica. Ver Frances Yates (2007) e Mary Carruthers (2008).

4 Importante ressaltar o debate atual, entre historiadores e críticos de arte, sobre a reescrita da história (oficial) da arte, quanto à noção de "Arte Conceitual", o que pressupõe a atualização e expansão dos "arquivos" dessa história (OSBORNE, 2002; FREIRE, 2006). Ao se considerar os "conceitualismos" produzidos na América Latina, na época, por artistas como Hélio Oiticica, Lygia Clark, Artur Barrio, entre outros, suas obras não se encaixam na definição hegemônica de Arte Conceitual.

5 Para uma definição do termo mapeado pela história da arte, ver Critical Terms for Art History. Edited by Robert S. Nelson and Richard Shif. The University of Chicago Press, 2003, 2nd ed.

6 Sobre a questão da citação e da cópia na poesia contemporânea, chamo atenção para a reflexão de Marjorie Perloff em 0 gênio não original (2010) e a análise do livro Passagens (19281940), de Walter Benjamin, como paradigma da poética citacional.

7 Ver Ana Pato, Literatura expandida: arquivo e citação na obra de Dominique GonzalezFoerster. São Paulo: Edições Sesc SP; Associação Cultural Videobrasil, 2012.

8 Notadamente, é no século 19 que a organização cronológica do arquivo baseada na capacidade de situar os documentos apartados de seu tempo como condição para uma leitura linear da história assume o papel de instituição central na formação dos Estados modernos e contemporâneos.

9 Sob esse aspecto, retomemos a leitura de Giulio Argan (1992, p. 356) sobre o movimento dadá. Diz ele que a Primeira Guerra Mundial representa "um desvio fatal da linha 'racional' da história", e os dadaístas estarão entre aqueles que vão compreender a guerra como "consequência lógica do progresso científico e tecnológico". O readymade de Marcel Duchamp representa o ponto máximo da "negação das técnicas como operações programadas". Os dadaístas vão propor uma ação perturbadora, com o objetivo de colocar o sistema em crise pelos seus próprios procedimentos, em que "a lógica não é senão uma interpretação, entre tantas possíveis, da 'lei do acaso"'.

10 Nos referimos à crítica ao modelo de racionalidade científica como concepção que compreende o conhecimento mais por sua capacidade de dominar e transformar, que como possibilidade de apreender profundamente a realidade. Sob esse ponto de vista, ver a reflexão de Boaventura de Souza Santos Um discurso sobre as ciências (1988, p. 19). Diz ele, "A ciência 
moderna não é a única explicação possível da realidade e não há sequer qualquer razão científica para a considerar melhor que as explicações alternativas da metafísica, da astrologia, da religião, da arte ou da poesia. A razão por que privilegiamos hoje uma forma de conhecimento assente na previsão e no controlo dos fenômenos nada tem de científico. É um juízo de valor. A explicação científica dos fenômenos é a autojustificação da ciência enquanto fenômeno central da nossa contemporaneidade. A ciência é, assim, autobiográfica".

11 Árvore-Escola" foi um trabalho realizado pelo Grupo Contrafilé, do qual Joana Zatz Mussi faz parte, em parceria com o coletivo palestino Campus in Camps e colaboração de diversos parceiros: TC Silva, Pedro Cesarino, Eugênio Lima, Assentamento Terra Vista, entre outros. Parte do trabalho foi realizada no Sul da Bahia, criando uma conexão entre quilombolas, Movimento sem Terra e refugiados palestinos. O trabalho foi comissionado pela 31a Bienal de São Paulo com apoio do FfAI (Foudation for Art Initiatives). Como resultado do processo, foi feita uma instalação na exposição e um livro impresso. O livro encontra-se disponível em: http://www.bienal.org.br/content/Arvore \%20Escola_Livro\%20DIGITAL.pdf.

12 Este seminário foi acessado em: Forensic Architecture, em várias ocasiões entre setembro de 2014 e maio de 2015. Disponível em: http://www.forensic-architecture.org/seminar/aesthetics-ofevidencel.

13 Os artistas que fazem parte de Meta-arquivo são Ana Vaz, Grupo Contrafilé, O Grupo Inteiro, Giselle Beiguelman, Ícaro Lira, Mabe Bethônico, Paulo Nazareth, Rafael Pagatini e Traplev. A exposição acontece de agosto a novembro de 2019, no Sesc Belenzinho, em São Paulo. 